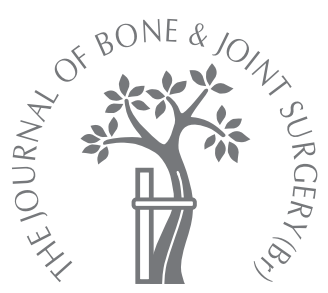

G. F. Dall, N. E. Ohly, J. A. Ballantyne, I. J. Brenkel

From Victoria Hospital, Fife, Scotland

In. F. Dall, MBBS, MRCSEd, Orthopaedic Registrar N. E. Ohly, MBChB(Ed), MRCSEd, Orthopaedic Registrar

New Royal Infirmary of Edinburgh, 51 Little France Crescent, Edinburgh EH16 4SA UK.

J. A. Ballantyne, BSc, $\mathrm{MBChB}$ (Trauma and Orth),

FRCS, Consultant Orthopaedic Surgeon

I. J. Brenkel, BSc, BSc, MBChB(Trauma and Orth),

FRCS, Consultant Orthopaedic Surgeon

Victoria Hospital, Hayfield Road, Kirkcaldy, Fife KY2 5AH UK.

Correspondence should be sent to Mr G. F. Dall; e-mail: gdall@nhs.net

(c)2009 British Editorial Society of Bone and Joint Surgery doi:10.1302/0301-620X.91B4 $21505 \$ 2.00$

$J$ Bone Joint Surg $[\mathrm{Br}]$ 2009;91-B:434-40. Received 8 July 2008; Accepted after revision 15 December 2008

\section{The influence of pre-operative factors on the length of in-patient stay following primary total hip replacement for osteoarthritis}

\author{
A MULTIVARIATE ANALYSIS OF 2302 PATIENTS
}

\begin{abstract}
We analysed which pre-operative factors could be used to predict the length of in-patient stay following unilateral primary total hip replacement undertaken for osteoarthritis. Data were collected prospectively from 2302 patients undergoing primary total hip replacement over a nine-year period. The relationships between the various pre-operative factors and length of stay were studied separately using either Student's t-test or Pearson's correlation, and then subjected to multiple linear regression analysis.

The mean length of stay was 8.1 days (median 7; 3 to 58). After adjusting for the effects of other pre-operative factors, younger age, male gender, higher combined Harris hip function and activity score, higher general health perception dimension of the Short-Form 36 score, and non-steroidal anti-inflammatory drug use were all found to be significantly associated with a reduced length of stay.
\end{abstract}

Primary total hip replacement (THR) is one of the most common surgical procedures, with approximately 202000 performed in the United States and 62000 in the United Kingdom per year. ${ }^{1-3}$ By 2030, it is estimated that 572000 primary THRs will be carried out annually in the United States alone. ${ }^{4}$ It is also one of the most cost-effective operations performed, with a high Quality of Life Adjusted Year (QUALY) index despite being associated with a relatively high initial average cost of $\$ 35$ 000. ${ }^{1}$

Since the 1970s clinical pathways have been used with the primary aim of improving the quality of in-patient care and patient satisfaction following THR. Previous studies examining the role of clinical pathways have shown that it is possible to reduce the length of stay and costs in acute care facilities while still safeguarding standards of patient safety and maintaining the same discharge goals. ${ }^{5,6}$

Factors shown to increase the length of stay following primary THR include increased age, ${ }^{7-11}$ female gender, ${ }^{7-9}$ high body mass index (BMI), ${ }^{11-14}$ smoking, ${ }^{13-15}$ low hip scores, ${ }^{16,17}$ not being married, and African-American ethnicity. ${ }^{18}$ However, these studies were retrospective and either involved small numbers, focused on a limited number of variables, or were not subject to robust statistical analysis. A more recent multivariate analysis of 712 patients $^{19}$ has also demonstrated a correlation between the length of stay and age, gen- der, marital status, medical comorbidities, American Society of Anaesthesiologists (ASA) grade and pre-operative level of haemoglobin.

It would be useful to be able to predict which factors affect the length of stay following THR. This would allow units to improve patient flow and thereby increase efficiency by optimising the case-mix and staffing levels in all related departments. Furthermore, more accurate information could be given to patients pre-operatively, enabling better management of patient expectation. We hypothesised that there are a number of pre-operative factors that would predict the length of in-patient stay following a unilateral primary THR. In order to test this hypothesis we carried out a multiple logistic regression analysis on data collected over a nine-year period.

\section{Patients and Methods}

Our dedicated elective orthopaedic unit consists of a 28-bed ward attached to an operating suite that runs 17 half-day operating sessions per week. Approximately 300 primary THRs are performed per annum on an almost exclusively Caucasian population. Since January 1998 prospective data have been collected on all patients undergoing primary THR. Specialist nurses interview each patient during the pre-assessment appointment and prospectively enter data into a Microsoft Excel database. Further data are collected during the in-patient stay and following discharge. Apart from 
length of stay, no other post-operative data were analysed in our study, with length of stay defined as the number of post-operative nights before discharge.

During the period of the study a total of 17 surgeons performed or supervised the operations, although on average there were only eight surgeons involved in a given year. All surgeons used a standard anterolateral approach, and all components were cemented. Charnley all-polyethylene acetabular components (DePuy, Leeds, United Kingdom) were used in all cases, and either Charnley (DePuy) or Lubinus SPII femoral components (Link, Hamburg, Germany) were used.

Every patient followed the same clinical pathway postoperatively with mobilisation the day after surgery. Routine blood tests were taken on the first and fourth days. Patients were discharged back to their pre-operative residence when they were deemed to be able to function independently, transfer safely, manage stairs if appropriate, and had a dry wound. There was no physiotherapy service at the weekend and no wound drains were used. Thromboembolic prophylaxis was not standardised throughout the study period. Initially this involved the use of graduated compression stockings, with anti-thrombotic drugs being prescribed according to surgeon preference. Since 2004 routine use of low molecular weight heparin for a total of ten days postoperatively has been adopted with patients completing the course at home. Patients deemed at high risk of thromboembolic disease are given $2.5 \mathrm{mg} \mathrm{s} / \mathrm{c}$ of fondaparinux sodium (GlaxoSmithKline, Uxbridge, United Kingdom) eight hours post-operatively, and the once daily for four weeks.

We identified 2547 consecutive patients over the nine-year period from 1 January 1998 to 1 January 2007. Exclusion criteria were bilateral simultaneous THR (99 patients), a diagnosis other than primary osteoarthritis (137 patients), and patients who had died during the initial admission for THR (nine patients). The remaining 2302 patients were anonymised and entered into the study.

The pre-operative factors that were recorded included age, gender, BMI, date of operation, surgeon, pre-operative haemoglobin, Harris hip score (HHS), ${ }^{20,21}$ Short-Form 36 (SF-36) score, ${ }^{22}$ Scottish Index of Multiple Deprivation, ${ }^{23}$ knee pain, back pain, contralateral hip pain, ischaemic heart disease, diabetes mellitus, other medical comorbidities, smoking and use of pre-operative aspirin or nonsteroidal anti-inflammatory drugs (Table I).

From the HHS we extracted the combined function/ activity dimension, which takes into account whether patients had a limp or used a walking aid, their walking distance, the ability to use public transport, to use stairs and to put on socks, and the length of time they are able to sit without pain. This permitted a score between 0 and 47 to be generated. From the SF-36 score we calculated the general perception dimension from responses to four statements: 'I seem to get sick a little easier than other people', 'I am as healthy as anybody I know', 'I expect my health to get worse' and 'My health is excellent'. Patients were required to indicate how strongly they agreed or disagreed with each statement, and a total score of between 0 and 100 was calculated.

The Scottish Index of Multiple Deprivation is a government tool for identifying local concentrations with multiple deprivations across 6000 small areas in Scotland. It is generated from a postcode and produces a ranking index by weighting the sum of a series of seven domains: current income, employment, health, education, skills and training, geographic access to services, housing and crime.

Ischaemic heart disease and diabetes mellitus were analysed individually. Other comorbidities grouped together for analysis included peripheral vascular disease, hypertension, osteoporosis, phlebitis, previous thromboembolic disease and malignancy. Other musculoskeletal pathology involving the knees, the contralateral hip and the lumbar spine were graded by the patient as normal, abnormal or disabling.

Statistical analysis. Data analysis was performed retrospectively by an independent statistician using SPSS 15 software (SPSS Inc., Chicago, Illinois). The mean length of stay was 8.1 days (median $7.0,3$ to 58 ). This indicated that the data were highly skewed, and so the statistical analysis was based on the logarithm of length of stay, which had an approximately symmetrical distribution. The relationship between each factor and length of stay was analysed separately using the $t$-test or Pearson's correlation. Multiple linear regression was used to analyse the effect of each significant factor adjusted for others. Because of the logarithmic transformation, the coefficients from this model convert to percentage differences in length of stay between the categories of each factor. Statistical significance was assumed when a p-value of $<0.05$ was obtained.

\section{Results}

The pre-operative factors that were not significantly associated with the length of stay included BMI, Scottish index of multiple deprivation score, and disabling knee, back or contralateral hip pain. A number of pre-operative factors were found to be highly significant predictors of length of stay when subjected to univariate analysis, but were not significant after multivariate analysis; these included smoking, ischaemic hip disease, diabetes mellitus, preoperative aspirin use, the pre-operative haemoglobin level and overall SF-36 score (Table I).

Multivariate logistic regression revealed that length of stay was significantly associated with age at the time of operation, gender, pre-operative use of non-steroidal antiinflammatory drugs (NSAIDs), surgeon performing the operation, the day of the week and the year of surgery, the combined function/activity dimension of the HHS, and the general health perception dimension of the SF-36 score (Table I). 
Table I. Statistical analyses of the influence of various factors on length of stay

\begin{tabular}{|c|c|c|c|c|}
\hline Factor $^{*}$ & Number of patients & Mean length of stay (days) & Univariate $\mathbf{p}$-value & $\begin{array}{l}\text { Multivariate } \\
\text { p-value }\end{array}$ \\
\hline \multicolumn{5}{|l|}{ Age (yrs) } \\
\hline$<60$ & 376 & 6.5 & & \\
\hline 60 to 70 & 788 & 7.1 & $<0.001$ & $<0.001$ \\
\hline 70 to 80 & 839 & 8.7 & & \\
\hline$>80$ & 299 & 11.5 & & \\
\hline \multicolumn{5}{|l|}{ Gender } \\
\hline Male & 843 & 7.5 & $<0.001$ & $<0.001$ \\
\hline Female & 1459 & 8.5 & & \\
\hline \multicolumn{5}{|l|}{$\mathrm{BMI}^{\dagger}$} \\
\hline$<18.5$ & 19 & 9.1 & & \\
\hline 18.5 to 25 & 602 & 8.3 & & \\
\hline 25 to 30 & 878 & 7.9 & 0.46 & $(\ddagger)$ \\
\hline 30 to 40 & 696 & 8.2 & & \\
\hline$>40$ & 27 & 8.2 & & \\
\hline \multicolumn{5}{|l|}{ Day of operation } \\
\hline Sunday & 18 & 9.3 & & \\
\hline Monday & 655 & 8.1 & & \\
\hline Tuesday & 303 & 8.3 & & \\
\hline Wednesday & 434 & 8.2 & $<0.001$ & 0.001 \\
\hline Thursday & 558 & 8.2 & & \\
\hline Friday & 317 & 7.8 & & \\
\hline Saturday & 17 & 7.2 & & \\
\hline \multicolumn{5}{|l|}{ Year of admission } \\
\hline 1998 to 1999 & 456 & 8.8 & & \\
\hline 2000 to 2001 & 471 & 8.2 & & \\
\hline 2002 to 2003 & 446 & 8.1 & $<0.001$ & 0.008 \\
\hline 2004 to 2005 & 552 & 8.2 & & \\
\hline 2006 to 2007 & 377 & 7.2 & & \\
\hline \multicolumn{5}{|l|}{ Knees $^{\dagger}$} \\
\hline Normal & 1771 & 8.1 & & \\
\hline Abnormal & 158 & 8.4 & 0.60 & $(*)$ \\
\hline Disabling & 354 & 8.1 & & \\
\hline \multicolumn{5}{|l|}{ Back $^{\dagger}$} \\
\hline Normal & 1568 & 8.1 & & \\
\hline Abnormal & 210 & 8.2 & 0.83 & $(*)$ \\
\hline Disabling & 510 & 8.1 & & \\
\hline \multicolumn{5}{|c|}{ Other musculoskeletal problems ${ }^{\dagger}$} \\
\hline Normal & 1955 & 8.2 & & \\
\hline Abnormal & 140 & 7.9 & 0.13 & $(*)$ \\
\hline Disabling & 194 & 7.7 & & \\
\hline \multicolumn{5}{|c|}{ Medical comorbidities ${ }^{\dagger}$} \\
\hline Yes & 1061 & 7.6 & $<0.001$ & 0.12 \\
\hline No & 1234 & 8.6 & & \\
\hline \multicolumn{5}{|c|}{ Ischaemic heart disease ${ }^{\dagger}$} \\
\hline Yes & 324 & 9 & $<0.001$ & 0.59 \\
\hline No & 1971 & 8 & & \\
\hline \multicolumn{5}{|l|}{ Diabetic $^{\dagger}$} \\
\hline Yes & 158 & 9.1 & 0.002 & 0.06 \\
\hline No & 2137 & 8.1 & & \\
\hline \multicolumn{5}{|l|}{ NSAIDs $^{\dagger}$} \\
\hline Yes & 1011 & 7.6 & $<0.001$ & $<0.001$ \\
\hline No & 1284 & 8.5 & & \\
\hline
\end{tabular}


Table I. Continued

\begin{tabular}{|c|c|c|c|c|}
\hline Factor $^{*}$ & Number of patients & Mean length of stay (days) & Univariate p-value & $\begin{array}{l}\text { Multivariate } \\
\text { p-value }\end{array}$ \\
\hline Yes & 520 & 8.7 & $<0.001$ & 0.07 \\
\hline No & 1775 & 8 & & \\
\hline \multicolumn{5}{|l|}{ Smoker ${ }^{\dagger}$} \\
\hline Ex & 742 & 8.1 & & \\
\hline \multicolumn{5}{|c|}{ Pre-operative haemoglobin level (g/l) } \\
\hline$<12$ & 291 & 9.6 & & \\
\hline 12 to 13 & 471 & 8.3 & & \\
\hline \multicolumn{5}{|c|}{ Consultant code ${ }^{\dagger}$} \\
\hline 1 & 111 & 8.4 & $<0.001$ & $<0.001$ \\
\hline 2 & 251 & 8.1 & & \\
\hline 3 & 196 & 9.3 & & \\
\hline 4 & 211 & 8.5 & & \\
\hline 5 & 242 & 8.2 & & \\
\hline 6 & 253 & 8.4 & & \\
\hline 7 & 547 & 8 & & \\
\hline 12 & 200 & 7.9 & & \\
\hline 14 & 138 & 6.4 & & \\
\hline \multicolumn{5}{|c|}{ Scottish Index of Multiple Deprivation ${ }^{\dagger}$} \\
\hline 5 & 293 & 8.3 & & \\
\hline \multicolumn{5}{|c|}{ Harris hip score (total) ${ }^{\dagger}$} \\
\hline 0 to 34 & 487 & 9.6 & & \\
\hline 35 to 44 & 634 & 8.3 & $<0.001$ & 0.67 \\
\hline 45 to 54 & 625 & 7.6 & & \\
\hline 55 to 100 & 515 & 7.1 & & \\
\hline \multicolumn{5}{|c|}{ Harris hip score (pain) ${ }^{\dagger}$} \\
\hline 0 & 7 & 9.7 & $<0.001$ & 0.44 \\
\hline 10 & 1585 & 8.4 & & \\
\hline 20 & 679 & 7.5 & & \\
\hline 30 & 27 & 7.1 & & \\
\hline 44 & 2 & 8.5 & & \\
\hline \multicolumn{5}{|c|}{ Harris hip score (function and activity) ${ }^{\dagger}$} \\
\hline 0 to 19 & 571 & 9.4 & & \\
\hline 20 to 25 & 473 & 8.3 & $<0.001$ & $<0.001$ \\
\hline 26 to 31 & 593 & 7.9 & & \\
\hline 32 to 47 & 637 & 7 & & \\
\hline \multicolumn{5}{|c|}{ Harris hip score (movement) ${ }^{\dagger}$} \\
\hline \multicolumn{5}{|c|}{ SF-36 physical functioning ${ }^{\dagger}$} \\
\hline
\end{tabular}


Table I. Continued

\begin{tabular}{|c|c|c|c|c|}
\hline Factor $^{*}$ & Number of patients & Mean length of stay (days) & Univariate $p$-value & $\begin{array}{l}\text { Multivariate } \\
\text { p-value }\end{array}$ \\
\hline \multicolumn{5}{|c|}{ SF-36 role physical $^{\dagger}$} \\
\hline 0 & 1525 & 8 & & \\
\hline 25 & 93 & 7.6 & & \\
\hline 50 & 67 & 7.1 & 0.001 & 0.12 \\
\hline 75 to 100 & 88 & 7.1 & & \\
\hline \multicolumn{5}{|l|}{ SF-36 Pain ${ }^{\dagger}$} \\
\hline 0 & 123 & 9.1 & $<0.001$ & 0.81 \\
\hline 11 to 22 & 1182 & 8.2 & & \\
\hline 33 & 461 & 7.9 & & \\
\hline 44 to 100 & 503 & 7.8 & & \\
\hline \multicolumn{5}{|c|}{ SF-36 general health perception ${ }^{\dagger}$} \\
\hline 0 to 49 & 160 & 9.2 & & \\
\hline 50 to 60 & 288 & 8.3 & & \\
\hline 70 to 89 & 1064 & 8.3 & $<0.001$ & 0.003 \\
\hline 90 to 100 & 748 & 7.5 & & \\
\hline \multicolumn{5}{|l|}{ SF-36 vitality ${ }^{\dagger}$} \\
\hline 0 to 25 & 431 & 8.6 & & \\
\hline 30 to 40 & 491 & 8.6 & & \\
\hline 45 to 60 & 693 & 8 & $<0.001$ & 0.58 \\
\hline 65 to 100 & 646 & 7.5 & & \\
\hline \multicolumn{5}{|c|}{ SF-36 social role functioning ${ }^{\dagger}$} \\
\hline 0 to 22 & 488 & 8.9 & & \\
\hline 33 to 44 & 539 & 8.2 & & \\
\hline 56 to 67 & 400 & 8.1 & $<0.001$ & 0.43 \\
\hline 78 to 100 & 839 & 7.6 & & \\
\hline \multicolumn{5}{|c|}{ SF-36 emotional role functioning ${ }^{\dagger}$} \\
\hline 0 & 322 & 8 & & \\
\hline 33 & 37 & 6.9 & & \\
\hline 67 & 25 & 8 & 0.98 & $(*)$ \\
\hline 100 & 1390 & 7.9 & & \\
\hline \multicolumn{5}{|c|}{ SF-36 mental health ${ }^{\dagger}$} \\
\hline 0 to 60 & 474 & 8.6 & & \\
\hline 64 to 76 & 570 & 8.1 & & \\
\hline 80 to 88 & 707 & 7.9 & $<0.001$ & 0.22 \\
\hline 92 to 100 & 510 & 7.9 & & \\
\hline \multicolumn{5}{|c|}{ SF-36 combined health ${ }^{\dagger}$} \\
\hline 0 & 119 & 8.4 & & \\
\hline 25 & 448 & 8.8 & & \\
\hline 50 & 1587 & 7.9 & $<0.001$ & 0.28 \\
\hline 75 to 100 & 113 & 8 & & \\
\hline
\end{tabular}

* BMI, body mass index; NSAIDs, non-steroidal anti-inflammatory drugs; SF-36, short-form 36

$\dagger$ some missing data

$\ddagger$ not included in multivariate analysis as not significant on univariate analysis

The $95 \%$ confidence limits for the effect sizes of each highly significant independent factor, expressed as a percentage difference from either a reference category or the calculated mean of each factor, are presented in Table II.

\section{Discussion}

The results confirm our hypothesis that there are a number of independent pre-operative factors that can be used to predict the length of stay following a unilateral primary THR. Most of our findings confirm those of earlier studies, particularly the relationships between increased length of stay and older age t-11,16,24-26 and female gender. ${ }^{7-9}$ Oldmeadow, McBurney and Robertson ${ }^{27}$ have shown that several factors, including age, gender and locomotor function, could predict the destination of the patient after discharge from hospital. They devised a formula to calculate 
Table II. The $95 \%$ confidence limits for effect sizes of highly significant factors adjusted for one another

\begin{tabular}{|c|c|}
\hline Factor $^{*}$ & $95 \%$ confidence limits ${ }^{\dagger}$ \\
\hline \multicolumn{2}{|l|}{ Age } \\
\hline Increase of ten years ${ }^{\ddagger}$ & 14 to 17 \\
\hline \multicolumn{2}{|l|}{ Gender } \\
\hline Female vs male & 4 to 10 \\
\hline \multicolumn{2}{|l|}{ HHS function/activity score } \\
\hline Increase of 10 units $^{5}$ & -8 to -5 \\
\hline \multicolumn{2}{|l|}{ SF-36 GHP } \\
\hline Increase of 10 units $\pi$ & -2 to -1 \\
\hline \multicolumn{2}{|l|}{ NSAIDs } \\
\hline Present $v s$ absent & -8 to -3 \\
\hline \multicolumn{2}{|l|}{ Consultant } \\
\hline Code 3 vs code 7 & 5 to 19 \\
\hline \multicolumn{2}{|l|}{ Year of admission } \\
\hline Increase of ten years & -15 to -4 \\
\hline \multicolumn{2}{|l|}{ Day of operation } \\
\hline Tuesday vs Monday & 2 to 14 \\
\hline \multicolumn{2}{|c|}{$\begin{array}{l}\text { * HHS, Harris hip score; SF-36, short-form 36; GHP, general health } \\
\text { perception; NSAIDs, non-steroidal anti-inflammatory drugs }\end{array}$} \\
\hline \multicolumn{2}{|c|}{$\dagger$ expressed as a percentage of median stay } \\
\hline \multicolumn{2}{|c|}{ ‡ from mean age of population } \\
\hline \multicolumn{2}{|c|}{$\S$ from means score in population ( 0 to 47 ) } \\
\hline If from mean score in pop & \\
\hline
\end{tabular}

the risk of extended in-patient rehabilitation, but their predictive factors were generated through literature review and expert opinion. Additionally the group they studied was small (520 patients) and included those undergoing all types of hip and knee arthroplasty, including primary and revision, and hemiarthroplasty of the hip. Thus, only tentative comparisons between the papers can be drawn.

We believe that two significant factors identified by our study have not been previously reported. There was a significant association between a high SF-36 general health perception score and shorter length of stay, which may reflect increased motivation and expectation in this group. The combined function/activity dimension of the HHS was also strongly associated with the length of stay. For example, a patient scoring seven points would be expected to stay between $20 \%$ and $28 \%$ longer than a matched patient scoring the maximum of 47 points. Although they used a different measure, Husted et $\mathrm{al}^{19}$ reported an association between the pre-operative use of a walking aid and an increased length of stay. This is consistent with our finding, the use of a walking aid being one of the criteria in the validated HHS function/activity assessment.

The requirement for regular NSAID medication preoperatively was also associated with a significantly shorter length of stay, and we wondered if this contributed to reduced post-operative pain and swelling in this group.
We also noted a significant association between the surgeon and the length of stay, but this could include variations in surgical technique, operating schedule, anaesthetic technique and pre-operative counselling. However, it is impossible to explore this further within the limitations of the study design.

Some of the negative findings in our study were surprising. Several previous studies have shown that high BMI, ${ }^{11-14}$ smoking ${ }^{13,15}$ and diabetes mellitus ${ }^{24}$ are all associated with an increased length of stay, but no such association was identified in our study. Conversely, our series demonstrated a trend that smoking was actually associated with a reduced length of stay $(\mathrm{p}=0.008)$, and there was only a trend towards increased length of stay in diabetic patients after multivariate analysis $(\mathrm{p}=0.06)$. A large multivariate analysis $^{13}$ on the impact of tobacco use and obesity in patients undergoing THR identified that these factors were associated with an increase in the complication rate but were not related to an increased length of stay.

The day of surgery did not influence the length of stay, as we had anticipated. In common with many institutions no physiotherapy services were available at the weekend. Previous authors ${ }^{19}$ have suggested that for this reason, surgery at the end of the week can lead to an increased length of stay. However, we found the shortest length of stay occurred in those patients undergoing surgery on a Friday. More analysis of this is needed before conclusions can be drawn.

We believe this study has several strengths. The length of stay of a large number of well-defined patients has been analysed using prospectively gathered data. However, we acknowledge the limitation that the database was not set up primarily to study the length of stay. Consequently, we did not have complete information relating to social circumstances, cognitive scores, objective measures of locomotor function or details of anti-coagulation with warfarin. Furthermore, data from multiple centres and from a more ethnically diverse population would have added to the strength of this study.

Further work will hopefully validate a simple scoring system which will predict the length of in-patient stay. Although the length of stay itself may not actually be reduced, an improvement in efficiency and patient flow through the hospital might result from advanced knowledge of the requirement for resources. Patient satisfaction and exceptions might also be better managed with more accurate forecasting of the likely length of stay. Obviously, intra- or post-operative complications will increase the length of stay, but these generally cannot be foreseen and their effects are currently the subject of a separate research project by our unit.

In conclusion, younger age, male gender, higher combined Harris hip function and activity score, higher general health perception dimension of SF-36 score and NSAID use are all significantly associated with reduced length of stay following primary THR for osteoarthritis. 
All patients gave informed consent to participate in the study, and the study was approved by the Fife NHS institutional review board. The authors would like to thank specialist arthroplasty nurses Mrs A. Simpson, L. McComiskie and S. Wilson for maintaining the database. Thanks also to $\mathrm{Dr}$ R. Elton for providing the statistical analysis.

Although none of the authors has received or will receive benefits for personal or professional use from a commercial party related directly or indirectly to the subject of this article, benefits have been or will be received but will be directed solely to a research fund, foundation, educational institution, or other non-profit organisation with which one or more of the authors are associated.

\section{References}

1. Zhan C, Kaczmarek R, Loyo-Berrios N, Sangl J, Bright RA. Incidence and shortterm outcomes of primary and revision hip replacement in the United States. J Bone Joint Surg [Am] 2007;89-A:526-33.

2. Drury P, Morrison J, Newill C. National Joint Registry for England and Wales 4th Annual Report. 2007:4 www.njrcentre.org.uk/njrcentre (date last accessed 2nd March 2009).

3. Brenkel I, Howie C. Scottish Arthroplasty Project Annual Report 2007. www.arthro.scot.nhs.uk (date last accessed 2nd March 2009).

4. Kurtz S, Ong K, Lau E, Mowat F, Halpern M. Projections of primary and revision hip and knee arthroplasty in the United States from 2005 to 2030. J Bone Joint Surg [Am] 2007;89-A:780-5

5. Healy WL, Ayers ME, lorio R, et al. Impact of a clinical pathway and implant standardization on total hip arthroplasty: a clinical and economic study of short-term patient outcome. J Arthroplasty 1998;13:266-76.

6. Walter FL, Bass N, Bock G, Marckel DC. Success of clinical pathways for total joint arthroplasty in a community hospital. Clin Orthop 2007;457:133-7.

7. Bozic KJ, Wagie A, Naessens JM, Berry DJ, Rubash HE. Predictors of discharge to an inpatient extended care facility after total hip or knee arthroplasty. J Arthroplasty 2006;21(6 Suppl 2):151-6.

8. Husted WH, Holm G, Rud K, et al. Length of stay after primary total hip and knee arthroplasty in Denmark, 2001-2003. Ugeskr Laeger 2006;168:276-9 (in Danish).

9. Vincent HK, Alfano AP, Lee L, Vincent KR. Sex and age effects on outcomes of total hip arthroplasty after inpatient rehabilitation. Arch Phys Med Rehabil 2006;87:461-7.

10. Weber EW, Slappendel R, Prins MH, et al. Perioperative blood transfusions and delayed wound healing after hip replacement surgery: effects on duration of hospitalization. Anesth Analg 2005;100:1416-21.

11. de Pablo P, Losina E, Phillips CB, et al. Determinants of discharge destination following elective total hip replacement. Arthritis Rheum 2004;51:1009-7.
12. Patel VP, Walsh M, Sehgal B, et al. Factors associated with prolonged wound drainage after primary total hip and knee arthroplasty. J Bone Joint Surg [Am]2007;89-A:33-8.

13. Sadr Azodi O, Bellocco R, Eriksson K, Adami J. The impact of tobacco use and body mass index on the length of stay in hospital and the risk of post-operative complications among patients undergoing total hip replacement. J Bone Joint Surg [Br]2006;88-B:1316-20.

14. Vincent HK, Weng JP, Vincent KR. Effect of obesity on inpatient rehabilitation outcomes after total hip arthroplasty. Obesity (Silver Spring) 2007;15:522-30.

15. Moller AM, Pedersen T, Villebro N, Munksgaard A. Effect of smoking on early complications after elective orthopaedic surgery. J Bone Joint Surg [Br]2003;85-B:178-81.

16. Hayes JH, Cleary R, Gillespie WJ, Pinder IM, Sher JL. Are clinical and patient assessed outcomes affected by reducing length of hospital stay for total hip arthroplasty? J Arthroplasty 2000;15:448-52

17. Scheerlinck T, Duquet W, Castelyn PP. Socioeconomic aspects of total hip arthroplasty: a one-year survey in a Belgian university hospital. Acta Orthop Belg 2004;70:525-33.

18. Lin JJ, Kaplan RJ. Multivariate analysis of the factors affecting duration of acute inpatient rehabilitation after hip and knee arthroplasty. Am J Phys Med Rehabil 2004;83:344-52.

19. Husted H, Holm G, Jacobsen S. Predictors of length of stay and patient satisfaction after hip and knee replacement surgery: fast-track experience in 712 patients. Acta Orthop 2008;79:168-73

20. Harris WH. Traumatic arthritis of the hip after dislocation and acetabular fractures: treatment by mold arthroplasty: an end-result study using a new method of result evaluation. $J$ Bone Joint Surg [Am] 1969;51-A:737-55

21. Murray DW, Fitzpatrick R, Rogers K, et al. The use of the Oxford hip and knee scores. J Bone Joint Surg [Br]2007;89-B:1010-14.

22. Jenkinson C, Layte R, Wright L, Coulter A. The UK SF-36: an analysis and interpretation manual. Oxford: Oxford University Press, 1996.

23. No authors listed. Scottish index of multiple deprivation. www.scotland.gov.uk/Topics/ statistics/SMID/Overview (date last accessed 2nd March 2009).

24. Forrest G, Fuchs M, Gutierrez A, Girardy J. Factors affecting length of stay and need for rehabilitation after hip and knee arthroplasty. J Arthroplasty 1998;13:186-90.

25. Rissanan P, Aro S, Paavolainen P. Hospital- and patient-related characteristics determining length of hospital stay for hip and knee replacements. Int $\mathbf{J}$ Technol Assess Health Care 1996;12:325-35.

26. Pettine KA, Aamlid BC, Cabanela ME. Elective total hip arthroplasty in patients older than 80 years of age. Clin Orthop 1991;266:127-32.

27. Oldmeadow LB, McBurney H, Robertson VJ. Predicting risk of extended inpatient rehabilitation after hip or knee arthroplasty. J Arthroplasty 2003;18:775-9. 